\title{
Tapping into past design experiences: knowledge sharing and creation during novice-expert design consultations
}

\author{
Fleur Deken - Maaike Kleinsmann • \\ Marco Aurisicchio - Kristina Lauche • \\ Rob Bracewell
}

Received: 15 October 2010/Revised: 30 September 2011/Accepted: 1 October 2011/Published online: 28 October 2011

(C) The Author(s) 2011. This article is published with open access at Springerlink.com

\begin{abstract}
Designing is a knowledge-intensive activity. For novice design engineers, an important means of acquiring knowledge is to consult experienced colleagues. We observed novice-expert consultations as part of three engineering projects in a large aerospace company. Seven meetings were analysed in detail regarding the design activity, the content, and the form of interaction. Although the meetings were initiated for the purpose of information seeking, this process amounted to only $8 \%$ of the time compared to knowledge creation between novices and experts ( $47 \%$ of meeting time), and contextual information sharing ( $45 \%$ of meeting time). Both experts and novices were found to contribute equally and interactively to the discussion and analysis of solutions. The analysis showed how the processes alternated in the meetings. We identified tentative patterns on how these consultation processes change over the course of the design process phases. The micro-level analysis of the design activities and form of
\end{abstract}

F. Deken $(\bowtie) \cdot$ M. Kleinsmann

Department of Product Innovation Management,

Delft University of Technology, Landbergstraat 15,

2628 CE Delft, The Netherlands

e-mail: f.deken@tudelft.nl

M. Aurisicchio

Department of Mechanical Engineering, Imperial College

London, Exhibition Road, South Kensington,

London SW7 2AZ, UK

K. Lauche

Institute for Management Research, Radboud University

Nijmegen, Thomas van Aquinostraat 3, 6500 HK Nijmegen,

The Netherlands

R. Bracewell

Engineering Design Centre, Cambridge University,

Trumpington St, Cambridge CB2 1PZ, UK interaction provided a deeper understanding of how the consultation processes are discursively produced by the experts and novices. Finally, implications for design engineering practitioners are derived and suggestions for further research are provided.

Keywords Design activity - Design knowledge · Protocol analysis · Novices · Information seeking

\section{Introduction}

Acquiring relevant information is an important task for industrial design engineers (Ahmed and Wallace 2004b; Wild et al. 2010; Badke-Schaub 2004; Marsh 1997; Restrepo 2004), since the quality of the design outcome is dependent on it (Badke-Schaub and Frankenberger 1999). Due to the complexity of today's design engineering projects, knowledge from different fields needs to be integrated in a design. Although it is common practice to work in multidisciplinary teams, this is not a guarantee that all necessary knowledge will be readily available in the team. Also engineering design practice has changed from using predominantly design and manufacturing information to now also including in-service information, as was shown by Jagtap and Johnson (2011) in the aerospace industry.

Empirical studies reported that aerospace engineers spent on average up to $80 \%$ of their workday searching for information (King et al. 1994). Research into information searches of different types of design engineers found that the majority of information searches occur via face-to-face interactions with other people (e.g. Court 1997; BadkeSchaub and Frankenberger 1999; Wallace and Ahmed 2003), rather than searching for information in a documentary source. Information management researchers 
investigating the use of social sources reported different percentages. Court et al. (1996) reported that 36\% of information was accessed through a person based on in their study in seven UK engineering companies in different domains; Marsh (1997) found that $90 \%$ of information was accessed through a person based on his study in a major aerospace engineering company. An explanation for the prevalence of using social sources is that people can translate their knowledge and apply it to a new context through reasoning processes (Aurisicchio et al. 2010). In addition, people can provide a rationale of past solutions (Bracewell et al. 1999) - a need identified as one of the most significant information needs in engineering companies (Heisig et al. 2010). Therefore, despite the advent of information technology systems, inter-personal communication remains a vital means for sharing knowledge and information within organisations (Mengis and Eppler 2008).

For novices that are new to design engineering practice, acquiring information is even more important since they have, by definition, less specialised knowledge to rely upon than experienced design engineers. Additionally, novices are also organisational newcomers and as such have a limited understanding of organisational aspects, such as an organisation's culture and procedures (Miller and Jablin 1991). Due to these knowledge gaps, they have different learning needs compared to experienced organisational members. In particular, novices need to learn what is expected of them (Miller and Jablin 1991), how to carry out their tasks, and where to find knowledge in the organisation (Penual and Cohen 2003). To assist organisational newcomers in their learning, companies set up training programmes, in which they are brought into contact with experienced organisational members "to rub elbows" (Penual and Cohen 2003). Such programmes aim to train newcomers in acquiring knowledge from their senior colleagues to use it in their own projects.

The present research project was situated at such a training programme for engineering graduates that were new to both the company and design engineering practice. Our research objective was to understand how novice and experienced design engineers exchange information during consultation meetings. The research had three aims: (1) to conceptualise the underlying consultation processes that occur during such meetings both on a macro-level and a micro-level; (2) to identify how experts can assist in satisfying novices' knowledge needs; and (3) to investigate whether the consultation processes change over the course of the novices' design process.

The paper is structured as follows. First, the literature is reviewed to identify the circumstances in which design engineers consult other people rather than documentary sources. Furthermore, literature on design expertise is integrated to understand how experts can potentially contribute to novices' projects. The extant literature on novice-expert consultations is summarised. Then, the methodology employed and the findings from the empirical study are presented. These are followed by our conceptualisation of design consultation meetings based on the observations and the fine-grained protocol analysis. Finally, suggestions for further research and implications for design engineering practice and research are provided.

\section{Consulting social sources to acquire knowledge and information}

Since this research addresses knowledge and information processes in novice-expert consultations, the literature on engineers' information seeking behaviour is reviewed to identify factors that influence source selection and the reasons why design engineers turn to colleagues during their information searches.

Firstly, the design process phase (e.g. Pahl and Beitz 1984) influences the information source selection. In their study in an international oil and gas company, Ellis and Haugan (1997) found that formal sources were most often used during early design process phases, i.e. task clarification and concept development, with usage decreasing over time. The usage of social sources became more dominant during later design phases. Secondly, the nature of the task influences information seeking behaviour. Milewski (2007) found that during factual tasks, software engineers often consult documentary sources, whereas during diagnostic problem-solving tasks they consult social sources. In addition, Restrepo and Christiaans (2004) found that designers consult social sources during problem structuring activities and documentary sources during problem-solving activities. Thirdly, the complexity of the problem at hand influences source selection. Aurisicchio et al. (2006) found that aerospace design engineers prefer consulting colleagues when working on complex problems. Finally, the level of expertise of a design engineer potentially influences source selection. Kwasitsu (2003) found that the higher the level of an engineer's education, the less likely the engineer is to rely on colleagues for their information needs. This finding could indicate that novice design engineers are more likely to search for information by addressing social sources.

Past research found several explanations why design engineers prefer to consult social sources. von Krogh et al. (2000) stated that through conversations with colleagues, new knowledge can be created, which is unlikely to result from interacting with documentary sources. Furthermore, Hertzum and Pejtersen (2000) suggested that people refer to social sources because they are able to elaborate on the context of a problem, whereas contextual information is 
often not captured, nor taken into account, in documentary sources. Similarly, Hertzum (2000) indicated that design engineers prefer to address social sources because people have the ability to surpass the current state of affairs and envision new solutions. Finally, Aurisicchio et al. (2010) reasoned that design engineers address social sources because certain requests for problem-solving assistance can only be satisfied by making inferences involving intellectual effort, a prerogative of people. The intellectual effort involved in responding to an information processing request is higher compared to the effort involved in reconstructing past project information, since new reasoning is needed. Furthermore, the authors argued that, besides satisfying information needs through addressing social sources, other benefits for consulting people exist-such as building social networks.

\subsection{Consulting design expertise}

Research on expertise found that it typically takes 10 years of extensive practice to become an expert in a specific field (Ericsson and Lehmann 1996). Several empirical studies have investigated the nature of design expertise in specific. Most aimed at identifying the differences between novice and expert design engineers. The literature was reviewed to understand what experts could potentially contribute to novices' projects.

The most obvious difference between an expert and novice is that an expert has more detailed domain knowledge (Sonnentag 2000). Furthermore, the way experts structure their knowledge also differs: experts store their knowledge in larger chunks (Cross 2004; Petre 2004; Akin 1990) and create integrated knowledge structures (Sonnentag 2000). Due to these integrated structures, experts can, for instance, focus their solution search effort more effectively to the more fruitful areas of the solution space, since they have an overview of the interaction and trade-offs between different variables, and they can reduce the complexity of the design engineering context to its fundamentals (Petre 2004).

Furthermore, experts are assumed to have different procedural knowledge. Experts develop guiding principles that help them prioritise and find direction in the design process (Lawson 1990, 2004). The expertise model developed by Kruger (1999) identified problem-solving knowledge as one of the characteristic knowledge types of experts, which can be seen as a type of procedural knowledge. Liikkanen and Perttula (2009) studied novice designers in the concept development phase and found that they often refrained from explicit problem decomposition. The authors suggested that this could explained by the novices' limited domain-relevant knowledge, which makes a decomposition strategy inefficient.
Finally, and potentially most importantly, what distinguishes experts from novices is the difference in experiential knowledge (Lawson 2004). As Lawson points out, it is not declarative knowledge structures that enable design engineers to proceed from a problem to a solution in a single step, but rather making analogies between past experiences and the current problem by retrieving part design episodes and generating new solutions based on that knowledge (Hargadon 1998; Hargadon and Sutton 1997). This process is facilitated by experts' developed thinking processes that are based on knowledge structures regarding typical events, which enables experts to apply knowledge in a new context without having to go through extensive analysis of the past solution itself-a process also known as analogical reasoning (Lawson 2004; Casakin 2004; Ball et al. 2004). Therefore, what distinguishes experts from novice design engineers is that experts are able to apply their experience and understanding of past solutions in new projects. An example of the usage of experiential knowledge by experts is what Ahmed et al. (2003) called the preliminary evaluation loop. The authors identified that the main behavioural pattern on which experts differed from novice design engineers is that experts used a preliminary solution evaluation loop before they implemented the solution. The authors found that expert design engineers relied on their experience to execute such preliminary evaluations by reasoning whether a solution under consideration is worth pursuing. Similarly, Ericsson and Lehmann (1996), based on their extensive literature review on expertise in different domains, concluded that experts have the ability to accurately anticipate outcomes of actions.

Besides these cognitive differences between experts and novices, it is worth emphasising the context-dependent nature of expertise. The capabilities of experts are highly domain-bound, and, as such, the evaluation of a persons' expertise is context dependent (Hoffman et al. 1997).

Based on the differences outlined above, it is concluded that novices would consult experts with the intention (1) to elicit some of their domain-specific knowledge; (2) to get input regarding design processes and how to approach the design tasks based on the experts' procedural knowledge; (3) to tap into their experiential knowledge to learn about past solutions and how such solutions can be applied in the context of their project; and (4) to receive rapid feedback as to whether their proposed solutions are worth pursuing.

\subsection{Novice-expert interactions in design engineering}

Although the literature on design expertise is well developed, novice-expert interactions in the context of design engineering have been little explored. Key studies in this field are those of Eris and Leifer (2003) and Ahmed and 
Wallace (2004b), who focused on the expert side and the novice side of the interaction, respectively.

Eris and Leifer (2003) interviewed process experts, team members, and others to understand the responsibilities of process experts during expert-team interaction as part of a specific knowledge transfer programme in an industrial company. They identified seven responsibilities of process experts: (1) knowledge sharing; (2) process reference; (3) filling the gaps; (4) process improvement; (5) gaining social acceptance; (6) solution creation; and (7) tool utilisation. Although these responsibilities show a particular characteristic of a novice-expert consultation, this study does not show how experts interact with novices to fulfil these responsibilities.

Ahmed and Wallace (2004b) studied novices involved in a knowledge acquisition project in the aerospace industry to understand their knowledge needs. By analysing novices' questions and statements during novice-expert interactions, it was found that novices' knowledge needs can be classified into eleven classes: (1) obtaining information; (2) typical value; (3) terminology; (4) trade-offs; (5) how does it work; (6) why; (7) what issues to consider; (8) when to consider particular issues; (9) how to calculate; (10) design process; and (11) company process. The authors found that novices' queries can be classified as questions and statements, accounting for 71 and $29 \%$, respectively. Furthermore, novices were found to predominantly query existing bodies of knowledge, which is illustrated by the eleven categories. Since this study was executed in the context of a knowledge acquisition project, this could have influenced the external validity of the research.

As this review showed, the current understanding of novice-expert interactions in design engineering is still limited. The focus of previous research was either on elements not directly related to the interaction, e.g. experts' responsibilities, or on isolated elements of the interaction, e.g. novices' questions and statements, rather than on the discourse as a whole. Consequently, the results did not describe the processes that occur during novice-expert consultations. Furthermore, the context of novices' projects was neglected in previous studies and the studies refrained from a diachronic analysis.

\section{Methods}

In order to study novice-expert consultations within their organisational context, we opted for an observational field study. Since few studies have so far addressed the processes in novice-expert consultations, we adopted an inductive data analysis approach. The first author spent 7 weeks shadowing three novice teams and observing and recording consultation meetings. Based on the transcripts of these meetings, all authors engaged in identifying themes, which were then related to the literature and resulted in three coding schemes. The details of the research setting, the sample, and the coding are explained below.

\subsection{Research setting}

The research setting was the graduate training programme at Rolls-Royce Aerospace Engineering. The observed consultation meetings took place in the context of the trainees' Design and Make project, which forms part of their 20-month programme. The trainees can be considered novice design engineers because they were recent engineering graduates who held general engineering degrees. Therefore, they had little experience in solving design problems in an industrial setting. Prior to this project, the trainees had completed two placements working on engineering tasks not involving design work. Besides being novices to design engineering practice, the trainees were also new to the company. The experts in this research were Rolls-Royce employees who were identified by the trainees as suitable sources. Hence, we take expertise as socially situated and assessed by the specific context, following Hoffman et al. (1997). Locating the right experts in the organisation to seek assistance was part of the novices' information search; it often took the trainees several phone calls to locate the right expert. By means of a post-consultation questionnaire, we distinguished between meetings in which novices inquired about the experts' knowledge and meetings in which the novices addressed their questions to the wrong person. Hence, we only included meetings in our sample in which both novice and expert reported that an actual consultation had taken place.

Each team consisted of four male graduate trainees who worked on an engineering design task for a client in RollsRoyce. They had not previously worked together. During the first 7 weeks of the project, the teams developed a design concept, which they built and tested in the remaining 5 weeks. Each team worked on its own task. For the purpose of the trainee programme and this research, the tasks can be regarded as comparable in terms of their complexity. A brief synopsis of the projects is presented below:

- Team A designed and built a handheld measurement device for the leading edges of fan blades. Fan blades must be inspected periodically to assess the need for repair. The major requirements for the team were to enable a fast, cost efficient, and accurate measurement device to assess the proximity of the leading edge to the critical (repair) condition. 
- Team B developed and tested new vent pipe restrictor designs to decrease their propensity to blockage. The key issue was to develop a test rig for measuring the relative improvement of the proposed designs over the current design.

- Team C created a working model of a magnetic harmonic drive to demonstrate this novel technology and measure its efficiency and output torque. Their task included the development of computer simulations of the magnetic forces and corresponding torque output.

\subsection{Sample}

Our sample consists of seven meetings by three different teams across the design process phases (Pahl and Beitz 1984). Since the 'embodiment design phase' and the 'detailed design phase' were difficult to empirically distinguish between, we conflated these categories into the 'detailed design phase'. The novice-expert consultation meetings occurred naturally during the trainees' projects; given the complexity of the projects, the trainees often had to search for relevant knowledge as input to their problemsolving activities. Since the novices arranged the consultations with experts, they can be considered properly motivated to make the most out of each consultation.

We aimed to maximise variety of information needs and consultation patterns. Therefore, our selection criteria were as follows:

- An even meeting distribution over the different project phases (task clarification, conceptual design, and detailed design)

- An even meeting distribution over the three different teams.

A brief overview of the selected meetings and attendees is provided in Table 1. The meetings are presented in order of the timing in the design process phases: task clarification, conceptual design, and detailed design.
For the purpose of this study, we treat these meetings as instances of novice-expert consultation practices across the design process phases. Although each team was working on their own task, the processes are comparable in that the members had a similar educational background and they worked on projects similar in size, scope, and the process to be followed, i.e. all teams had to develop a concept design during the first 6 weeks of the project and to test a working prototype during the final 6 weeks. Since the further career path of the trainees was partly based on the their performance during the Design and Make project, the project coordinators took great care in selecting projects of comparable complexity to allow for a fair comparison.

\subsection{Data analysis}

The analysis was informed by the protocol-analysis tradition in design research (Cross et al. 1996; McDonnell and Lloyd 2009; Badke-Schaub and Frankenberger 1999). We analysed the inter-personal communication during naturally occurring design meetings (e.g. Luck and McDonnell 2006). The driving force behind the consultations was considered the novice's knowledge need (Ahmed and Wallace 2004a), since this is ultimately the cause for the interaction. Since the expert's response influences the outcome of the consultation and consequently the novice's satisfaction, the interactions were studied from both the novice's and the expert's perspective.

For further methodological inspiration, we drew on studies that focused on designer-user interactions (Luck and McDonnell 2006) and teacher-student interactions (Hmelo-Silver and Barrows 2008; Hogan et al. 1999). These studies illustrated that the relation between the speakers' conversational behaviour and the shared information could be investigated by adopting a detailed analysis strategy focusing on both conversation content and dynamics. Furthermore, the studies of Hmelo-Silver and Barrows (2008) and Hogan et al. (1999) illustrated that insightful relations can be identified between macro- and

Table 1 Meeting characteristics

\begin{tabular}{lllllll}
\hline Meeting & Team & Design process phase & Number of words & Duration & Expert(s) & Novice(s) \\
\hline 1 & B & Task clarification & 11,709 & $01: 07: 24$ & E1 & B1, B2, B3, B4 \\
2 & A & Task clarification & 7,698 & $00: 39: 30$ & E2, E3 & A1, A2, A3, A4 \\
3 & A & Conceptual design & 9,932 & $00: 54: 06$ & E4 & A1, A2, A3, A4 \\
4 & B & Conceptual design & 8,000 & $00: 43: 08$ & E4 & B1, B2 \\
5 & B & Conceptual design & 8,539 & $00: 50: 06$ & E5, E6 & B1, B2 \\
6 & C & Detailed design & 3,520 & $00: 27: 41$ & E7, E8 & C1 \\
7 & C & Detailed design & 9,771 & $01: 01: 01$ & E4 & C1 \\
\hline
\end{tabular}


micro-level investigation leading to more comprehensive characterisation of the discourse.

The starting point of our analysis (see Fig. 1) was the explicit properties of the verbal communication (Heritage 2001; Luck and McDonnell 2006), i.e. communication other than that expressed via the verbal communication channel was not taken into account. The explicit verbal communication was analysed in terms of: (1) the content of the communication and (2) the form of the communication. In the qualitative analysis of the content, we interpreted the verbal communication in terms of the type of activity that the novice and expert performed. The analysis of the form addressed how a message was phrased, i.e. as a question or statement (Ahmed and Wallace 2004b). The resulting conversational balance scheme captures the initiator and the provider of the information being exchanged in the interactions between expert and novice.

\subsubsection{Coding procedure}

Three coding schemes were inductively developed on different levels of analysis and then related to the literature, following Miles and Huberman (1994). All five authors read the meeting transcripts and the codes were developed through ongoing internal discussion. Several rounds of coding all data resulted in three final coding schemes. For the purpose of the code development and application, we used NVivo - a software tool that supports coding documents as part of qualitative analysis (Lewins and Silver 2007). The codes were mutually exclusive. After the final coding schemes were decided upon, the entire data set was recoded using all three final coding schemes. Both qualitative and quantitative analysis methods were used to further analyse and make sense of the codes' frequencies and the code patterns (Chi 1997). The six steps followed in developing the three coding schemes are explained below.

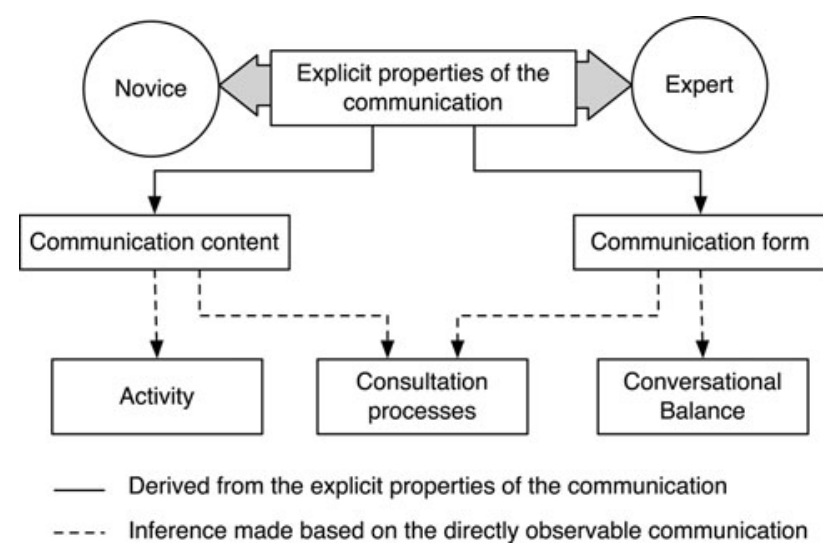

Fig. 1 Analysis framework for novice-expert interactions in design engineering
First, we inductively developed an initial set of consultation process codes based on the observations of the first author. These macro-codes were adjusted through interaction with the data and aimed at capturing the macroprocesses that occur during novice-expert consultation meetings. Then, the analysis of the type of utterances focused on the conversational turn. A turn is the speech uttered by one speaker before the floor is taken by another speaker (Hogan et al. 1999). Each conversational turn was classified as either a statement or a question (Ahmed and Wallace 2004b; Hmelo-Silver and Barrows 2008). When a question and statement were uttered within one conversational turn, it was decided to split these into two turns.

In the third step, episodes, i.e. chunks of the conversation focused on the same topic, were identified through the investigation into topic-changes or what Brown and Yule (1983) called 'topic boundary markers'. Then, conversational balance codes were identified through pattern finding based on the micro-level analysis. Three main modes were distinguished: discourse units, question-answer sequences, and interactive discussions. Discourse units are sequences of talk in which one speaker mainly contributes and the other speakers only support this contribution, e.g. agreeing or uttering a minimal response (Houtkoop and Mazeland 1985). A distinction was made between information pushes and information pulls to characterise the information flow in the interactions. This terminology was adapted from information technology research, e.g. Cybenko and Brewington (1999) where it is used to describe operations for addressing information resources.

Question-answer sequences were coded as either a novice pull or an expert pull; discourse units were coded as either a novice push or an expert push, depending on the initiator. When novices and experts were involved in interactive discussions, i.e. the novice and the expert took alternating turns in talking about a topic, this was coded as interactive. The initiator of an information push or pull is perceived to be the person who steers that part of the interaction. Observations regarding the identified episodes in step 3 showed that sometimes a question was posed but answered only later after a previous issue was resolved. In these instances, the question was coded as information pull and the corresponding response as a delayed answer. As such, the analysis of the conversation content informed the conversational balance coding.

The final list of conversational balance codes is shown in Table 2.

In the fifth step, we inferred the activity that was discursively performed based on the analysis of the episodes identified in step 3. A first version of this activity coding scheme was based on Stempfle and Badke-Schaub's (2002) category system, which served as a theoretical starting point open for further adjustments to fit to the data (Miles 
Table 2 Conversational balance codes

\begin{tabular}{ll}
\hline Categories & Description \\
\hline Expert push & Expert initiated sequence of statements in which the expert is the information provider \\
Expert pull & Expert initiated sequence resulting from a question, in which the novice is the information provider \\
Novice push & Novice initiated sequence of statements in which the novice is the information provider \\
Novice pull & Novice initiated sequence resulting from a question, in which the novice is the information provider \\
Expert delayed answer & Expert answer to a question earlier in the consultation asked by the novice \\
Novice delayed answer & Novice answer to a question earlier in the consultation asked by the expert \\
Interactive & Iterative expert and novice statements \\
\hline
\end{tabular}

Table 3 Activity codes

\begin{tabular}{|c|c|}
\hline Category & Description \\
\hline 1. Problem understanding & $\begin{array}{l}\text { Discussing the problem, its background, the causes of the problem, implications of the problem, } \\
\text { and the problem context of the novices' current project }\end{array}$ \\
\hline 2. Requirement finding & Defining, adjusting, adding, or sharing the requirements of the current task \\
\hline 3. Past design discussion & Discussing a past solution for both the current problem and other solutions \\
\hline 4. Solution explanation & Explaining potential solutions for the current project, generated before the consultation \\
\hline 5. Solution generation & Generation of new (sub-) solutions for the current project \\
\hline 6. Solution analysis & Predicting of behaviour, discussing judgments, or evaluating of (sub-) solutions \\
\hline 7. Decision making & Deciding regarding the design or design process \\
\hline 8. Design process & Discussing the process of the current project \\
\hline 9. Communication process & Meta-communication, introducing people, discussing meeting objectives \\
\hline 10. Organisational information sharing & Discussing company procedures, information sources, or expertise distribution in the company \\
\hline 11. Team coordination & Discussing the current and/or future collaboration between the expert and novice(s) \\
\hline
\end{tabular}

and Huberman 1994). The list of activity codes shown in Table 3 was refined through several alternations, which involved splitting up, merging, and adding codes based on the constant comparison of the different codes.

Finally, we revisited the consultation process codes identified in step 1 . The code combinations of the conversational balance and the activity coding schemes were mapped on the main consultation process codes. The micro-analysis was used to inform and inductively adjust the consultation process codes. The final consultation processes were the following: (1) information seeking, (2) knowledge creation, and (3) contextual information sharing. An overview of the consultation process code descriptions is provided in Table 4 . The different activity and conversational code combinations and the corresponding consultation process codes are provided in the Appendix. In coding the consultation processes, the episode, activity, and conversational balance were taken into account. For example, when a question-answer pattern occurred, this not automatically amounted to an information seeking process. It depended on the activity performed by means of the question-answer pattern, i.e. when a question by the novice was related to a solution generation activity, this was considered part of a knowledge creation process as this can be seen as asking generative questions (Eris 2004). The final analysis of the codes was performed by means of querying code frequencies in NVivo.

The inter-rater agreement was calculated (Wickens 1989) based on the codings of the first author and the second author of $10 \%$ of the sample. The Cohen's Kappa coefficients of 0.827 for the activity codes and 0.922 for the conversational balance codes indicate a high agreement between coders (Cohen 1960).

\section{Results}

In this section, the results of the in-depth analysis of the seven consultation meetings are presented. Starting with brief synopses of the meetings (see Table 5), the three main consultation processes identified in the research are presented. 
Table 4 Consultation process codes

\begin{tabular}{|c|c|}
\hline Categories & Description \\
\hline Information seeking & The explicit information requests, or questions, posed by novices and the corresponding expert reply \\
\hline Knowledge creation & Interactive discussions that involve the synthesis of new knowledge for the novices' task \\
\hline $\begin{array}{l}\text { Contextual information } \\
\text { sharing }\end{array}$ & $\begin{array}{l}\text { When novice and expert explained contextual information, e.g. their educational backgrounds or the history of the } \\
\text { task at hand }\end{array}$ \\
\hline
\end{tabular}

Table 5 Meeting synopses

\begin{tabular}{|c|c|}
\hline Meeting & Synopsis \\
\hline 1 & $\begin{array}{l}\text { Team B consulted an expert regarding the background of their design task. The consulted expert developed several redesigns in the } \\
\text { past, which were discussed extensively in the meeting }\end{array}$ \\
\hline 2 & $\begin{array}{l}\text { Team A met with two measurement specialists to better understand what requirements their measurement device must satisfy to go in } \\
\text { the after-sales market. The experts had much experience in developing such devices and provided process guidance and helped in } \\
\text { evaluating the team's early ideas regarding suitable measurement technologies }\end{array}$ \\
\hline 3 & $\begin{array}{l}\text { Team A met with a senior designer to evaluate their list of potential technologies for their measurement device. Much time was spent } \\
\text { on predicting the behaviour of the solutions }\end{array}$ \\
\hline 4 & $\begin{array}{l}\text { Two members of team B met with a senior designer to evaluate their test rig concept, develop, and explore new solutions for a number } \\
\text { of sub-problems }\end{array}$ \\
\hline 5 & $\begin{array}{l}\text { Two members of team B consulted two senior rig designers. The rig designers gave many practical tips and identified critical problems } \\
\text { in the trainee's rig design concept }\end{array}$ \\
\hline 6 & $\begin{array}{l}\text { A member of team } \mathrm{C} \text { approached two bearing designers to evaluate his concept design and his bearing calculations. The experts } \\
\text { proposed many changes and drew these in the trainee's CAD drawing. The bearing designers explained which variables to take into } \\
\text { account when selecting bearings }\end{array}$ \\
\hline 7 & $\begin{array}{l}\text { A member of team } \mathrm{C} \text { consulted two senior designers to receive feedback on his screw and thermal calculations. During the discussion, } \\
\text { the experts identified many new issues and tentative solutions were collaboratively generated and evaluated. The experts shared their } \\
\text { experiences in manufacturing a working model and provided the trainee with practical tips }\end{array}$ \\
\hline
\end{tabular}

\subsection{Consultation processes}

Three consultation processes were distinguished: information seeking, knowledge creation, and contextual information sharing. Table 6 shows the distribution of the three consultation processes in the seven meetings. The duration of the processes was estimated based on a word count, rather than on the actual time spent in each process. Since the coding schemes were based on different units of analysis and the codes often started at different points in the transcripts and even the smallest unit, the utterance often differed in length. Therefore, simply counting the co-occurrences of utterances between the two coding schemes was not an option. Instead, we counted the number of words coded to indicate the time spent. On $10 \%$ of the sample, we performed a correlation analysis between the number of words in the transcript coded as consultation process codes and the time spent on these processes using the audio files. This indicated a strong relationship between word count and time (Pearson's product-moment correlation coefficient $r=0.977, p<.000$ ).

The variation in time spent on the different processes is noticeable and can be explained by the fact that the meetings were captured during different phases of the design process. Overall, the results show that little time was spent on information seeking-on average 8\%compared to knowledge creation processes-on average $47 \%$-and contextual information sharing processes-on average $45 \%$.

A remarkable finding was how little the novices relied on explicit questioning to retrieve existing technical design information, as is employed in information seeking processes. Ahmed and Wallace (2004b) had found that novice-expert consultations contained many question-answer sequences. We however found they mostly engaged in knowledge creation, a process in which experts and novices collaboratively create new design knowledge. Considering that contextual information sharing constituted such a substantial part of novice-expert discourses, this process appears to be a supporting process of the information seeking and knowledge creation processes.

Table 6 shows the distribution of the three consultation processes across the design process phases. Information seeking decreased with the development of the project (Pearson's product-moment correlation coefficient $r=$ $-0.929, p<.01)$. Therefore, the more the design is defined, the less time the novices spent on explicitly querying the 
Table 6 Overview of consultation processes per meeting

\begin{tabular}{|c|c|c|c|c|c|c|c|c|}
\hline \multirow{2}{*}{$\begin{array}{l}\text { Process } \\
\text { Design } \\
\text { process phase }\end{array}$} & \multicolumn{7}{|l|}{ Meetings } & \multirow{2}{*}{$\begin{array}{l}\text { Average } \\
(\%)\end{array}$} \\
\hline & $\begin{array}{l}1 \\
\text { Task } \\
\text { clarification } \\
(\%)\end{array}$ & $\begin{array}{l}2 \\
\text { Task clarification }(\%)\end{array}$ & $\begin{array}{l}3 \\
\text { Conceptual } \\
\text { design } \\
(\%)\end{array}$ & $\begin{array}{l}4 \\
\text { Conceptual } \\
\text { design } \\
(\%)\end{array}$ & $\begin{array}{l}5 \\
\text { Conceptual } \\
\text { design } \\
(\%)\end{array}$ & $\begin{array}{l}6 \\
\text { Detailed } \\
\text { design } \\
(\%)\end{array}$ & $\begin{array}{l}7 \\
\text { Detailed } \\
\text { design } \\
(\%)\end{array}$ & \\
\hline Information seeking & 19.9 & 25.1 & 2.5 & 0.9 & 0.1 & 7.5 & 0.0 & 8 \\
\hline Knowledge creation & 23.6 & 35.4 & 47.0 & 66.2 & 64.2 & 39.2 & 51.6 & 47 \\
\hline Contextual information sharing & 56.6 & 39.5 & 50.4 & 32.9 & 35.7 & 53.3 & 48.4 & 45 \\
\hline Total & 100 & 100 & 100 & 100 & 100 & 100 & 100 & 100 \\
\hline
\end{tabular}

expert's knowledge. A significant positive correlation was found between the time spent on knowledge creation and the phases time scale $(r=0.857, p<.05)$. Knowledge creation rarely occurred early on in the process. We expected that at this phase of the project, novices would not yet engage in knowledge creation with the experts because they were still developing their problem understanding. However, in the conceptual and detailed design project phases, the time spent on this process increased. The time spent on contextual information sharing did not change across the process phases.

Although the results presented so far may suggest that the consultation processes evolved sequentially, the data analysis showed that the processes were fragmented and often alternated from one consultation process to another. On average, these switches occurred 56 times in a meeting $(\mathrm{SD}=22)$. Figure 2 shows the sequence of alternation between the consultation processes in the seven meetings. The horizontal axis represents the length of the meeting transcript. As such, the stripe length indicates the time spent on a particular process over the course of the meeting. When qualitatively inspecting these stripes, we found that in the task clarification phase (meetings 1 and 2) the alternations occurred in a more sequential fashion compared to a meeting during the conceptual design project phase (meetings 3, 4, and 5). The meetings in the task clarification phase started with longer periods of contextual information sharing that alternated with information seeking periods. Later in these meetings, alternations between contextual information sharing and knowledge creation emerged. It seems that sharing background information in the task clarification phase is discursively performed in larger chunks whereas it is more fragmented in the concept development phase. Figure 3 shows how often the six types of alternations occurred within one meeting as a percentage of the total alternations. It illustrates that in meetings 1 and 2 an even distribution of alternations occurred between contextual information sharing and information seeking (grey coloured segments) and between contextual information sharing and knowledge creation (white coloured segments).

In addition, we found indications that the contextual information sharing processes in the conceptual design phase were on average shorter compared to meetings in the task clarification phase, as is shown in Fig. 4. In meetings in the concept development phase, alternations between contextual information sharing and knowledge creation started from the beginning of the meeting onwards, see Fig. 2. This pattern does not hold for meeting 5, where much time is spent at the beginning of the meeting to establish a common understanding of the problem. A possible explanation for this discrepancy is that the consulted expert realised that he did not have the right expertise and asked a colleague to join the discussion, which led to more contextual information sharing to get his colleague up to speed.

It is noteworthy that in five out of seven meetings, the participants had not previously met. Only in meetings 4 and 7 , the novices met with an expert that they had already consulted. As it can be seen in Fig. 2, in these two meetings contextual information sharing and knowledge creation alternated at the beginning of the meeting, while most of the remaining meetings started with a more extensive contextual information sharing phase. This trend, however, was not found in meeting 3, where knowledge creation already occurred early.

\subsection{Discursively produced consultation processes}

To acquire a more in-depth understanding of the consultation processes, the transcripts were also analysed at a finer grain size. Investigating the activities performed in the meeting, more insights were gained regarding how the consultation processes are discursively produced by the expert and novice during the consultations. The combinations of the activity and conversational balance codes were found to map well in each of the three main consultation processes. For example, when an expert pushed new 
Fig. 2 Alternations between consultation phases in meetings $1-7$

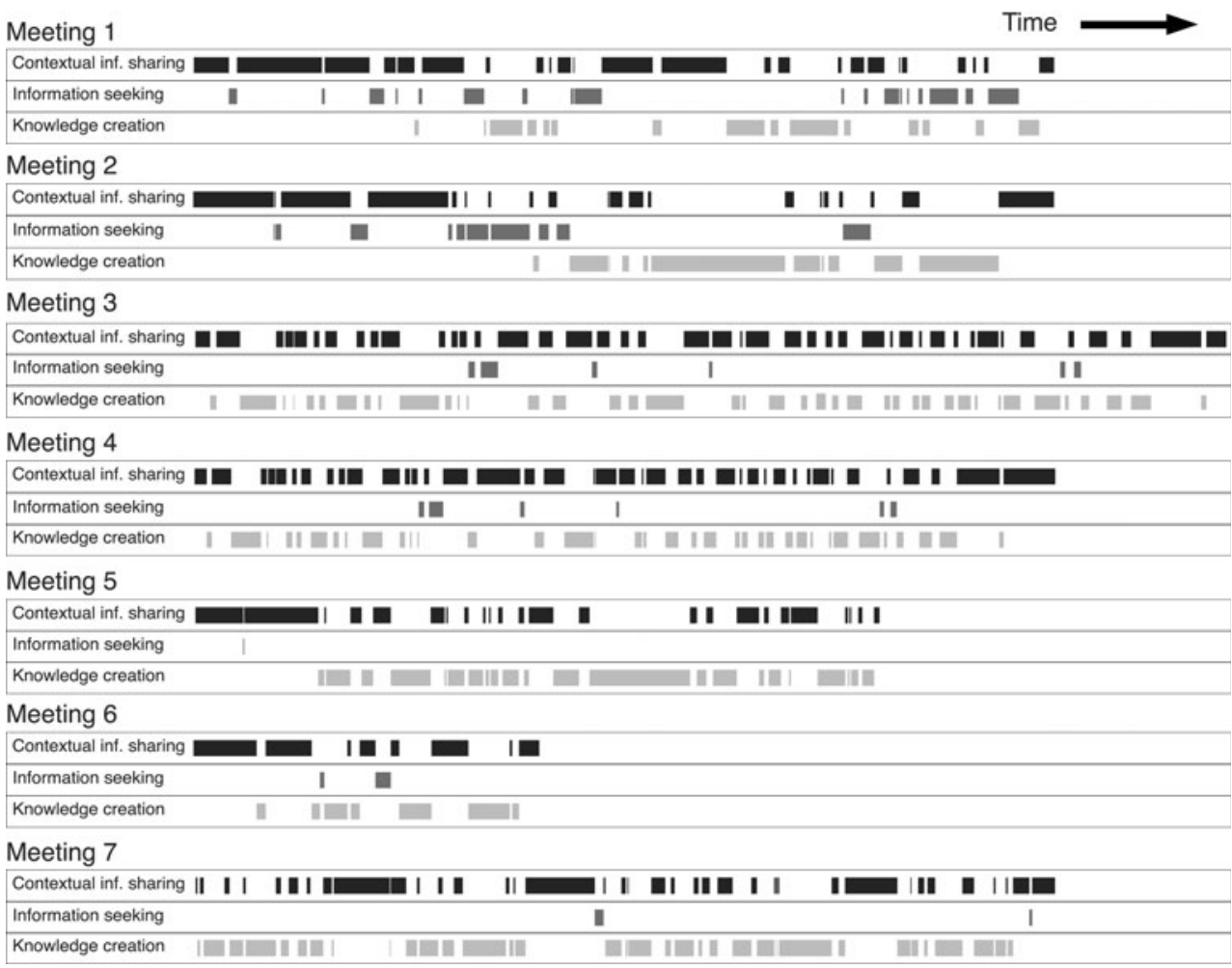

Fig. 3 Alternations between consultation processes compared between meetings

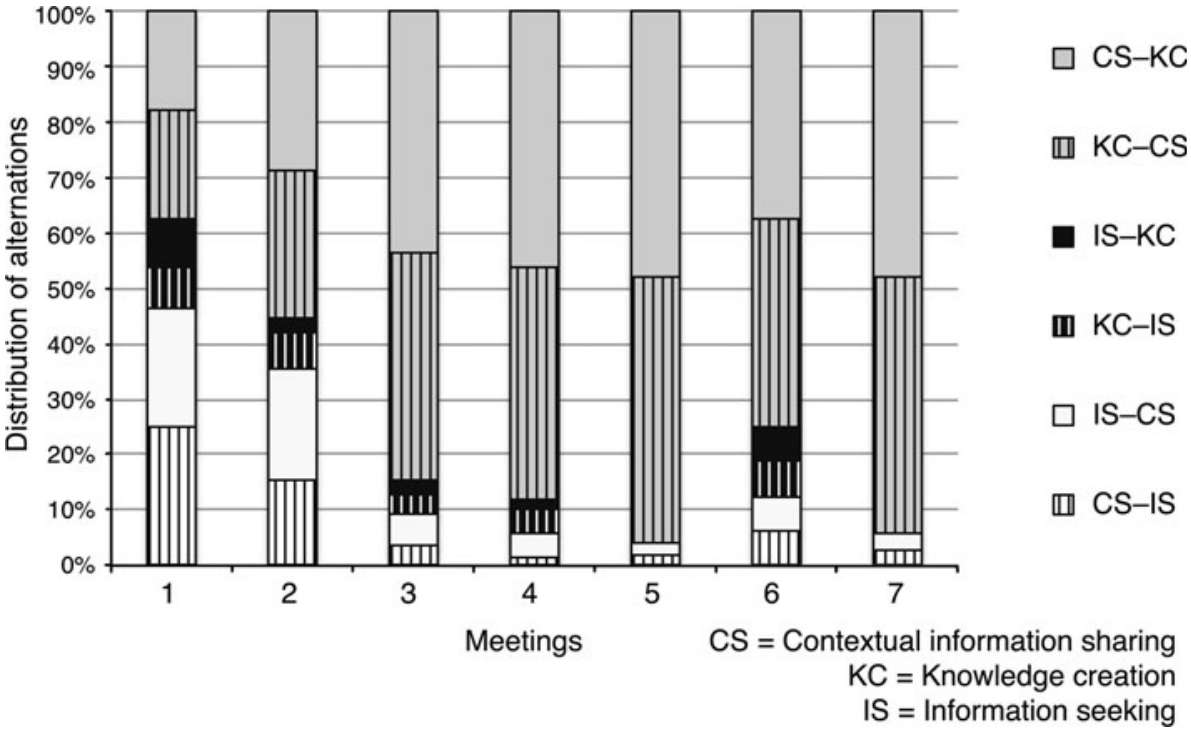

During the majority of knowledge creation episodes, the novice and expert collaboratively analysed solutions (25.6\%), and experts pushed their reasoning regarding solution analysis (22.3\%). To a lesser extent, experts generated new solution proposals (12.9\%) and expressed their views regarding the design process followed by the novices (10.9\%). When novices pulled new solutions from experts, this can be seen as asking generative questions (Eris 2004). Posing deep-reasoning questions was part of knowledge creation too and happens in the meeting when novices 


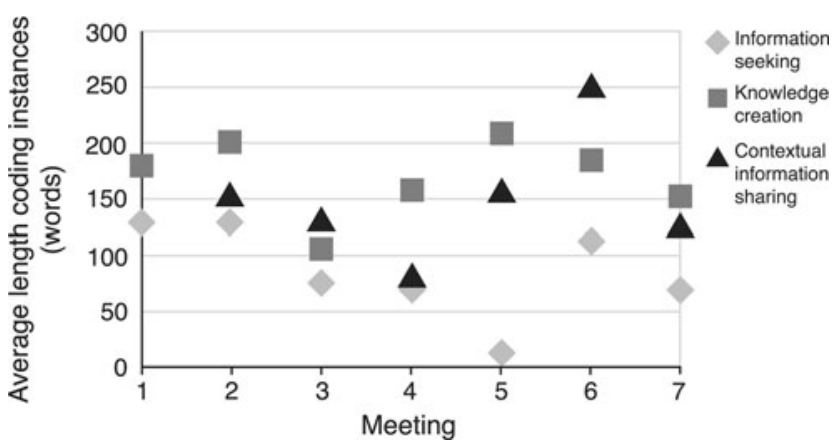

Fig. 4 Average length of consultation processes over the meetings

pulled a solution analysis regarding the solutions under consideration (Eris 2004). As the Appendix shows, however, little time was spent dealing with generative design questions posed by the novices compared to the time spent on deep-reasoning questions posed by the novice. Knowledge creation processes were mainly focused on generating and analysing new solutions. This was performed through collaborative reasoning discussions, or expert initiated discussions.

During contextual information sharing, many sub-processes occurred. Often, experts pushed information regarding past solutions $(16.4 \%)$ or expressed their insights regarding the novices' problem $(12.3 \%)$. To a lesser extent, experts inquired about the solutions the design team considered $(9.2 \%)$, and pushed organisational information $(8.5 \%)$. Furthermore, we found that novices shared the details of their task $(9.9 \%)$ and explained potential solutions $(9.2 \%)$ and their project's process $(8.1 \%)$. In summary, the contextual information sharing process was mainly focused on information exchanges regarding the novices' project. This was aimed at bringing the expert up to speed and transferring general organisational information, such as organisational protocols and the whereabouts of other potentially interesting experts for the novices to talk to.

\section{Discussion}

This study confirmed that novice-expert consultation meetings are opportunities for novices to acquire useful information and to create new knowledge about their design. We identified three main processes during consultations: knowledge creation, information seeking, and contextual information sharing. During information seeking, novices asked explicit questions to seek technical design information. During knowledge creation, novices generated new knowledge, and experts applied their experiential knowledge on the task so as to generate new knowledge about the design. Finally, during contextual information sharing, novices shared information about their task, and experts shared information about their expertise and ways of operating in the organisation.
Furthermore, the findings indicate that the time spent on the three main consultation processes changed throughout the design process phases. Across all meetings, the time spent on information seeking decreased, while the time spent on knowledge creation increased and that on contextual information sharing remained constant. While this finding needs to be treated with caution, as it is aggregated across three different projects, the prevalence of knowledge creation in later meetings could indicate that the novices used the meetings to draw on the experts' experiential knowledge in helping them think through a solution.

It was striking to find that so little time was spent on information seeking. The small number of explicitly posed questions contradicts the findings of Ahmed and Wallace (2004b) that novices posed explicit questions in $71 \%$ of their information queries. Their study also found that novices most often inquired about existing bodies of knowledge, whereas in our study it was found that knowledge creation occurred far more often than information seeking. These differences could be caused by the fact that the discourses studied in our research were captured as part of real design projects, whereas the discourses studied by Ahmed and Wallace originated from a knowledge capture project. Therefore, this research illustrates the importance of studying knowledge acquisition in its social context.

In this study, approximately half of the time was spent on contextual information sharing, which is a process that merely supports the information seeking and knowledge creation processes. This finding implies that during novice-expert interactions a substantial amount of contextual information needs to be shared between the speakers before they can focus on the actual information seeking and knowledge creation.

Based on the investigations into the micro-level, it was found that novices spent a substantial amount of time explaining project details and the design problem specifics. Increasing the expert's problem understanding appears to be a key task for novices to ensure a successful consultation. Only through sharing this contextual information, will the information provided and the knowledge created by the expert fit the specific novice's problem. Additionally, it was found that experts contributed to the novice's task by providing both design engineering knowledge and their experience, the first aiming to fill the knowledge and information gaps existing between novices and experts, as was also identified by Eris and Leifer (2003), and the second aiming to use the expert's experience as a resource for creating new knowledge about the design (von Krogh et al. 2000). The finding that the novices' knowledge needs were context-specific highlights the need for consulting social sources, as identified by previous studies (e.g. Hertzum 2000; Hertzum and Pejtersen 2000; Aurisicchio et al. 2010). 
Cross and Sproull (2004) stated that when a problem is not fully specified-which is common in design engineering practice-actors must first lay out the various problem dimensions before being able to generate solutions, a process included in our study in contextual information sharing. Several other studies also emphasised the importance of bridging consultation gaps between novices and experts by means of grounding. Clark and Brennan (1991) stated that during a conversation, speakers constantly need to update their common ground. They stated that actions executed collaboratively must be built upon common ground between speakers. These studies only described the need to get the novice up to speed with the experts' expertise; the present study also identified the need for sharing project and process information from the novices' side to get the expert up to speed with the novice's design problem. This constant process of creating common ground manifested itself in our study through the frequent alternation between the knowledge creation and contextual information sharing processes.

Our findings indicate that the novices' design problem formed the common ground between the novice and expert and facilitated the transfer of knowledge between them. The experts responded by applying their knowledge to the novice's problem without necessarily making this explicit. Similar to apprenticeship approaches to developing mastery experience (Collins et al. 1989), the novices were able to observe the expert's reasoning and approach and could model their own approach on their observations without the need for the expert to articulate their implicit knowledge. Similarly to Hargadon and Bechky (2006), the appropriate amount of contextual information sharing between the two parties seemed vital for the novices to 'pick the expert's brain'. Without sufficient contextual information, a novice risks asking questions that do not fit the expert's expertise, and the solutions generated by experts are likely to misfit the novice's design problem. Research on teams in which members hold partial information showed that people are more likely to discuss information they hold in common than to share complementary information (Stasser and Titus 1985, 1987). We believe, therefore, that it is a balancing act to mediate between sharing sufficient contextual information while, at the same time, spending sufficient time on the actual consultation process.

Finally, a tentative pattern was found that consultations follow a more sequential process in the task clarification phase compared to the conceptual design phase. This finding can be explained through the theory of the co-evolution of the design problem and solution as proposed by Dorst and Cross (2001). In meetings 1 and 2, the novices and the experts collaboratively set the problem through relatively long sequences of contextual information sharing, informed by periods of information seeking and knowledge creation. In the conceptual design phase, they alternated fast and often between contextual information sharing, which is instrumental in setting the problem, and knowledge creation, which was here instrumental in generating and evaluating solutions. It seemed that by creating solutions through collaborative knowledge creation, they also needed to deepen their understanding of the design problem at hand. The knowledge created about the (new) design problem through sequences of contextual information sharing formed the input for creating knowledge on (new) parts of the solution.

\subsection{Limitations and suggestions for further research}

A limitation of this study is the small number of meetings analysed. The meetings also originated from different albeit comparable projects, and it may be debatable if an aggregation across all meetings is actually meaningful. In-depth qualitative field research always faces such commensurability problems-neither can the data collection be intelligibly randomised nor can a sufficiently large sample be obtained to control for differences between the cases. Another limitation is that the meetings were gathered in one specific field of design engineering - namely the aerospace industry-and in only one company. In order to determine whether the findings could be generalised, more research into such consultation meetings in other organisations and design engineering fields would be needed.

This research developed and employed a conceptualisation of novice-expert consultations as a social process. In doing so, we acquired an understanding of the processes occurring during such consultations. Suggestions for further research are to investigate novices' behaviour in more depth and to identify strategies that novices can adopt when searching for expert input. Furthermore, the finding that the processes alternated often could be further investigated by analysing how the interaction changes and what the results for the conversation are. By means of such an investigation, the mechanisms that novices and experts can use to create common ground during consultations can be identified. In addition, future research could attempt to elucidate what constitutes an effective design consultation.

\subsection{Practical and theoretical implications}

In terms of practical implications, we believe that novice designers could be supported during organisational entry by heightening their awareness of consultation processes. By unravelling processes, activities, and conversational balances of consultations, structures and relations were found that can help novice and expert designers by increasing their understanding of elements in the 
conversation that are of importance during the meeting. Our study found that experts could help novices by improving their problem understanding, by providing them with design input in the form of solutions and analysis, and by increasing their organisational understanding. Trainee programmes could also include modules on knowledge elicitation strategies as used for requirement elicitation or in knowledge management (see for example Firlej and Hellens 1991) to enable novices to draw more effectively on the implicit knowledge of the experts.

Another practical implication for novices is the importance of sharing their project knowledge with expertsthrough contextual information sharing-to have an effective consultation. For novices, it might seem strange that sharing their knowledge is of much importance. Experts might respond as if they already understand the novice's design problem. With the novices rests the significant task of validating that the expert's understanding of their design problem is indeed correct.

In terms of theoretical implications, this study showed how novices acquire existing knowledge from experts and generate new knowledge during consultation meetings in the context of a multinational aerospace engineering company. Research in related fields confirms this role of consultation meetings as a means for information seeking. Berends et al. (2011) analysed such consultations in R\&D environments in the consumer electronics and the oil and gas industry. Hargadon and Bechky (2006) report similar consultations in design and strategy consultancy firms. While we cannot empirically generalise our particular findings, we believe these studies corroborate our findings and suggest that similar dynamics may occur in other knowledge-intensive industries.

This study contributes to design engineering research by showing how activities during interactions between novice and expert designers are related to the discourse characteristics, or in other words, showing 'what' is done 'how'. Furthermore, this study provided a research framework for studying design discourses on a fine-grained level, which could be of value for studying other types of design discourses, e.g. communication between designers or clientdesigner interactions.

\subsection{Conclusion}

This study found that novices acquire existing knowledge from experts and generate new knowledge together with experts during consultation meetings by means of three consultation processes: information seeking (on average $8 \%$ of meeting time), knowledge creation (on average
$47 \%$ of meeting time), and contextual information sharing (on average $45 \%$ of meeting time). Contextual information seeking was identified as a main supporting process: Without sharing sufficient contextual information, a novice risks asking questions that do not fit the expert's expertise, and the solutions generated by experts are unlikely to fit the novice's design problem. As such, this study indicates that novices and experts need to balance sharing sufficient contextual information with collaborating on the actual consultation request.

Over the course of the design process phases, the time spent on information seeking decreased, while the time spent on contextual information sharing remained constant and that on knowledge creation increased. In other words, the nature of the consultation changed in relation to the progression in the design process, moving from straightforward pieces of information to a co-design process.

Both experts and novices were found to contribute to the discussion and analysis of solutions, and as such, both have an important and different role in the consultation process. We found that the novice's design problem facilitated the transfer of knowledge between them as the expert could apply their knowledge to the novice's problem without necessarily making this explicit. This research stresses the importance of having small task-related social encounters, such as the novice-expert consultations, in which design engineering problems are discussed and collaboratively tackled, like the creative collectives described by Hargadon and Bechky (2006). These interactions enable the transfer and implementation of implicit knowledge. Since this knowledge is often of contemporary nature and not (yet) formally documented, interactions between designers while focusing on actual problems are major knowledge transfer and creation mechanisms, which should be valued accordingly.

Acknowledgments The authors acknowledge the support of RollsRoyce through the University Teaching Partnership for Design and in particular thank Dr. Michael Moss, Jim Wickerson, Roger Fountain, and the participating design engineers. We thank Dr. Yoram Reich and two anonymous reviewers for their feedback to further develop this paper.

Open Access This article is distributed under the terms of the Creative Commons Attribution Noncommercial License which permits any noncommercial use, distribution, and reproduction in any medium, provided the original author(s) and source are credited.

\section{Appendix}

See Table 7. 
Table 7 Occurrences of consultation processes, activities, and conversational balance

\begin{tabular}{|c|c|c|c|c|}
\hline \multirow{2}{*}{$\begin{array}{l}\text { Consultation process } \\
\text { Information seeking }\end{array}$} & \multirow[t]{2}{*}{ Activity } & \multirow[t]{2}{*}{ Conversational balance } & \multicolumn{2}{|c|}{ Occurrence } \\
\hline & & & \multicolumn{2}{|c|}{ Total $8 \%$ of the meeting } \\
\hline & Problem understanding & Novice pull/expert answer & 1,753 & $36.2 \%$ \\
\hline & Organisational information sharing & Novice pull/expert answer & 1,569 & $32.4 \%$ \\
\hline & Past design & Novice pull/expert answer & 822 & $17.0 \%$ \\
\hline & Team coordination & Novice pull/expert answer & 665 & $13.7 \%$ \\
\hline & Solution explanation & Novice pull/expert answer & 35 & $0.7 \%$ \\
\hline \multirow[t]{22}{*}{ Knowledge creation } & & & \multicolumn{2}{|c|}{ Total $47 \%$ of the meeting } \\
\hline & Solution analysis & Interactive & 7,148 & $25.6 \%$ \\
\hline & Solution analysis & Expert push & 6,225 & $22.3 \%$ \\
\hline & Solution generation & Expert push & 3,598 & $12.9 \%$ \\
\hline & Design process & Expert push & 3,050 & $10.9 \%$ \\
\hline & Solution analysis & Novice push & 2,246 & $8.0 \%$ \\
\hline & Solution analysis & Expert pull/novice answer & 1,206 & $4.3 \%$ \\
\hline & Solution analysis & Novice pull/expert answer & 1,119 & $4.0 \%$ \\
\hline & Design process & Novice pull/expert answer & 662 & $2.4 \%$ \\
\hline & Design process & Interactive & 607 & $2.2 \%$ \\
\hline & Solution generation & Interactive & 510 & $1.8 \%$ \\
\hline & Requirement finding & Expert push & 397 & $1.4 \%$ \\
\hline & Solution generation & Novice pull/expert answer & 360 & $1.3 \%$ \\
\hline & Requirement finding & Interactive & 311 & $1.1 \%$ \\
\hline & Requirement finding & Novice pull/expert answer & 203 & $0.7 \%$ \\
\hline & Requirement finding & Novice push & 93 & $0.3 \%$ \\
\hline & Requirement finding & Expert pull/novice answer & 91 & $0.3 \%$ \\
\hline & Decision making & Expert push & 74 & $0.3 \%$ \\
\hline & Decision making & Novice pull/expert answer & 31 & $0.1 \%$ \\
\hline & Decision making & Novice push & 10 & $0.0 \%$ \\
\hline & Decision making & Interactive & 0 & $0.0 \%$ \\
\hline & Decision making & Expert pull/novice answer & 0 & $0.0 \%$ \\
\hline \multirow[t]{18}{*}{ Contextual information sharing } & & & \multicolumn{2}{|c|}{ Total $45 \%$ of the meeting } \\
\hline & Past design & Expert push & 4,478 & $16.4 \%$ \\
\hline & Problem understanding & Expert push & 3,342 & $12.3 \%$ \\
\hline & Problem understanding & Novice push & 2,696 & $9.9 \%$ \\
\hline & Solution explanation & Novice push & 2,647 & $9.7 \%$ \\
\hline & Solution explanation & Expert pull/novice answer & 2,511 & $9.2 \%$ \\
\hline & Organisational information sharing & Expert push & 2,318 & $8.5 \%$ \\
\hline & Design process & Novice push & 2,195 & $8.1 \%$ \\
\hline & Problem understanding & Expert pull/novice answer & 1,191 & $4.4 \%$ \\
\hline & Team coordination & Expert push & 1,047 & $3.8 \%$ \\
\hline & Communication process & Expert push & 803 & $2.9 \%$ \\
\hline & Requirement finding & Novice push & 746 & $2.7 \%$ \\
\hline & Solution explanation & Expert push & 615 & $2.3 \%$ \\
\hline & Communication process & Expert pull/novice answer & 394 & $1.4 \%$ \\
\hline & Team coordination & Interactive & 386 & $1.4 \%$ \\
\hline & Requirement finding & Expert pull/novice answer & 380 & $1.4 \%$ \\
\hline & Communication process & Novice push & 370 & $1.4 \%$ \\
\hline & Design process & Expert pull/novice answer & 309 & $1.1 \%$ \\
\hline
\end{tabular}


Table 7 continued

\begin{tabular}{|c|c|c|c|c|}
\hline \multirow[t]{2}{*}{ Contextual information sharing } & \multirow[b]{2}{*}{ Team coordination } & \multirow[b]{2}{*}{ Expert pull/novice answer } & \multicolumn{2}{|c|}{ Total $45 \%$ of the meeting } \\
\hline & & & 175 & $0.6 \%$ \\
\hline & Past design & Novice push & 163 & $0.6 \%$ \\
\hline & Organisational information sharing & Novice push & 143 & $0.5 \%$ \\
\hline & Organisational information sharing & Interactive & 127 & $0.5 \%$ \\
\hline & Problem understanding & Interactive & 99 & $0.4 \%$ \\
\hline & Communication process & Interactive & 37 & $0.1 \%$ \\
\hline & Past design & Expert pull/novice answer & 31 & $0.1 \%$ \\
\hline & Communication process & Novice pull/expert answer & 30 & $0.1 \%$ \\
\hline & Organisational information Sharing & Expert pull/novice answer & 28 & $0.1 \%$ \\
\hline & Team coordination & Novice push & 0 & $0.0 \%$ \\
\hline & Past design & Interactive & 0 & $0.0 \%$ \\
\hline & Solution explanation & Interactive & 0 & $0.0 \%$ \\
\hline
\end{tabular}

\section{References}

Ahmed S, Wallace KM (2004a) Identifying and supporting the knowledge needs of novice designers within the aerospace industry. J Eng Des 15(5):475-492

Ahmed S, Wallace KM (2004b) Understanding the knowledge needs of novice designers in the aerospace industry. Des Stud 25(2): 155-173

Ahmed S, Wallace KM, Blessing LT (2003) Understanding the differences between how novice and experienced designers approach design tasks. Res Eng Des 14(1):1-11

Akin M (1990) Necessary conditions for design expertise and creativity. Des Stud 11(2):107-113

Aurisicchio M, Bracewell RH, Wallace KM (2006) Characterising in detail the information requests of engineering designers. In: Proceedings of ASME design theory and methodology, Philadelphia, PA, pp DETC/DTM-99418

Aurisicchio M, Bracewell R, Wallace K (2010) Understanding how the information requests of aerospace engineering designers influence information-seeking behaviour. J Eng Des 21(6): 707-730

Badke-Schaub P (2004) Strategies of experts in engineering design: between innovation and routine behaviour J Des Res 4(2). doi: 10.1504/JDR.2004.009837

Badke-Schaub P, Frankenberger E (1999) Analysis of design projects. Des Stud 20(5):465-480

Ball LJ, Omerod TC, Morely NJ (2004) Spontaneous analogising in engineering design: a comparative analysis of experts and novices. Des Stud 25(5):495-508

Berends H, Raghu G, Debackere K, Weggeman M (2011) Thinking along: a process for tapping into knowledge across boundaries. Int J Technol Manage 53(1):69-88

Bracewell R, Wallace KM, Moss M, Knott D (1999) Capturing design rationale. Comput Aided Des 41(3):173-186

Brown G, Yule G (1983) Discourse analysis. Cambridge University Press, Cambridge

Casakin H (2004) Visual analogy as a cognitive strategy in the design process: expert versus novice performance. J Des Res 4(2). doi: 10.1504/JDR.2004.009846

Chi MTH (1997) Quantifying qualitative analyses of verbal data: a practical guide. J Learn Sci 6(3):271-315

Clark HH, Brennan SE (1991) Grounding in communication. In: Resnick LB, Levine JM, Teasley SD (eds) Perspectives on socially shared cognition. American Psychological Association, Washington, pp 127-149
Cohen J (1960) A coefficient of agreement for nominal scales. Educ Psychol Meas 20(1):37-46

Collins A, Brown JS, Newman SE (1989) Cognitive apprenticeship. Teaching the crafts of reading, writing, and mathematics. In: Resnick LB (ed) Knowing, learning, and instruction. Erlbaum, Hilsdale, pp 453-494

Court AW (1997) The relationship between information and personal knowledge in new product development. Int $\mathrm{J}$ Inf Manage 17(2):123-138

Court AW, Culley SJ, McMahon CA (1996) Information access diagrams: a technique for analyzing the usage of design information. J Eng Des 53(4):384-403

Cross N (2004) Expertise in design: an overview. Des Stud 25(5): $427-441$

Cross R, Sproull L (2004) More than an answer: Information relationships for actionable knowledge. Organ Sci 15(4): $446-462$

Cross N, Christiaans H, Dorst K (eds) (1996) Analysing design activity. Wiley, Chichester

Cybenko G, Brewington B (1999) The foundations of information push and pull. In: Cybenko G, O'Leary DP, Rissanen J (eds) The mathematics of information coding, extraction, and distribution. The IMA volumes in mathematics and its applications, vol 107. Springer, New York, pp 9-30

Dorst K, Cross N (2001) Creativity in the design process: co-evolution of problem-solution. Des Stud 22:425-437

Ellis D, Haugan M (1997) Modelling the information seeking patterns of engineers and research scientists in an industrial environment. J Doc 53(4):384-403

Ericsson KA, Lehmann AC (1996) Expert and exceptional performance: evidence of maximal adaptation to task constraints. Annu Rev Psychol 47:273-305

Eris Ö (2004) Effective inquiry for innovative engineering design. Kluwer Academic Publishers, Boston

Eris Ö, Leifer L (2003) Facilitating product development knowledge acquisition: interaction between the expert and the team. Int $\mathbf{J}$ Eng Educ 19(1):142-152

Firlej M, Hellens D (1991) Knowledge elicitation: a practical handbook. Prentice Hall International Hertfordshire, London

Hargadon AB (1998) Firms as knowledge brokers: Lessons in pursuing continuous innovation. Calif Manage Rev 40(3): 209-227

Hargadon AB, Bechky BA (2006) When collections of creatives become creative collectives: a field study of problem solving at work. Organ Sci 17(4):484-500 
Hargadon AB, Sutton RI (1997) Technology brokering an innovating in a new product development firm. Adm Sci Q 42(4):716-749

Heisig P, Caldwell NHM, Grebici K, Clarkson PJ (2010) Exploring knowledge and information needs in engineering from the pats and for the future-results from a survey. Des Stud 31(5): 499-532

Heritage J (2001) Goffman, Garfinkel and conversation analysis. In: Wetherell M, Taylor S, Yates SJ (eds) Discourse theory and practice: a reader. Sage Publications, London, pp 47-56

Hertzum M (2000) People as carriers of experience and sources of commitment: information seeking in a software design project. N Rev Inf Behav Res 1(1):135-149

Hertzum M, Pejtersen AM (2000) The information-seeking practices of engineers: searching for documents as well as for people. Inf Process Manage 36(5):761-778

Hmelo-Silver CE, Barrows HS (2008) Facilitating collaborative knowledge building. Cogn Instr 26(1):48-94

Hoffman RR, Feltovich PJ, Ford KM (1997) A general conceptual framework for conceiving of expertise and expert system. In: Feltovich PJ, Ford KM, Hoffman RR (eds) Expertise in context: human and machine. MIT Press, Cambridge, pp 543-580

Hogan K, Nastasi B, Pressley M (1999) Discourse patterns and collaborative scientific reasoning in peer and teacher-guided discussions. Cogn Instr 17(4):379-432

Houtkoop H, Mazeland H (1985) Turns and discourse units in everyday conversation. J Pragmat 9(5):595-620

Jagtap S, Johnson A (2011) In-service information required by engineering designers. Res Eng Des. doi:10.1007/s00163-0110107-8

King DW, Casto J, Jones H (1994) Communication by engineers: a literature review of engineers' information needs, seeking processes, and use. Council on Library Resources, Washington

Kruger C (1999) Cognitive strategies in industrial design engineering. Dissertation, Delft University of Technology, Delft

Kwasitsu L (2003) Information-seeking behavior of design, process, and manufacturing engineers. Libr Inf Sci Res 25(4):459-476

Lawson B (1990) How designers think. Butterworth Architecture, London

Lawson B (2004) Schemata, gambits and precedent: some factors in design expertise. Des Stud 25(5):443-457

Lewins A, Silver C (2007) Using software in qualitative research: a step-by-step guide. Sage Publications, London

Liikkanen LA, Perttula M (2009) Exploring problem decomposition in conceptual design among novice designers. Des Stud 30(1): $38-59$

Luck R, McDonnell J (2006) Architect and user interaction: the spoken representation of form and functional meaning in early design conversations. Des Stud 27(2):141-166

Marsh JR (1997) The capture and structure of design experience. Dissertation, Cambridge University, Cambridge
McDonnell J, Lloyd P (eds) (2009) About: designing. Analysing design meetings. CRC Press, London

Mengis J, Eppler MJ (2008) Understanding and managing conversations from a knowledge perspective: an analysis of the roles and rules of face-to-face conversations in organizations. Organ Stud 29(10):1287-1313

Miles MB, Huberman AM (1994) Qualitative data analysis: an expanded sourcebook, 2nd edn. Sage Publications, London

Milewski AE (2007) Global and task effects in information-seeking among software engineers. Empir Softw Eng 12(3):311-326

Miller VD, Jablin FM (1991) Information seeking during organizational entry: influences, tactics, and a model of the process. Acad Manage Rev 16(1):92-120

Pahl G, Beitz W (1984) Engineering design. The Design Council, London

Penual B, Cohen A (2003) Coming to the crossroad of knowledge, learning and technology: integrating knowledge management and workplace learning. In: Ackerman MS, Pipek V, Wulf V (eds) Sharing expertise: beyond knowledge management. The MIT Press, Massachusetts, pp 57-76

Petre M (2004) How expert engineering teams use disciplines of innovation. Des Stud 25(5):477-493

Restrepo J (2004) Information processing in design. Dissertation, Delft University of Technology, Delft

Restrepo J, Christiaans H (2004) Problem structuring and information access in design. J Des Res 4(2). doi:10.1504/JDR.2004.009842

Sonnentag S (2000) Expertise at work: experience and excellent performance. In: Cooper CL, Robertson IT (eds) International review of industrial and organizational psychology. Wiley, Chichester, pp 223-264

Stasser G, Titus W (1985) Pooling of unshared information in group decision making: biased information sampling during discussion. J Personal Soc Psychol 48(6):1467-1478

Stasser G, Titus W (1987) Effects of information load and percentages of shared information on the dissemination of unshared information during group discussion. J Personal Soc Psychol 53(1):81-93

Stempfle J, Badke-Schaub P (2002) Thinking in design teams-an analysis of team communication. Des Stud 23:473-496

von Krogh G, Ichijo K, Nonaka I (2000) Enabling knowledge creation: how to unlock the mystery of tacit knowledge and release the power of innovation. Oxford University Press, Oxford

Wallace KM, Ahmed S (2003) How engineering designers obtain information. In: Lindemann U (ed) Human behaviour in design: individuals, teams, tools. Springer, Berlin, pp 184-194

Wickens TD (1989) Multiway contingency tables analysis for the social sciences. Lawrence Erlbaum Associates, Hillsdale

Wild PJ, McMahon CA, Shaofeng L (2010) A diary study of information needs and document usage in the engineering domain. Des Stud 31(1):46-73 